\title{
Surface functionalization of polyvinyl chloride by plasma immersion techniques
}

\author{
Péricles Lopes Sant'Ana1* (D), José Roberto Ribeiro Bortoleto' (D), Nilson Cristino da Cruz ${ }^{1}$ (D), \\ Elidiane Cipriano Range ${ }^{1}$ (D), Steven Frederick Durrant ${ }^{1}$ (D) and Wido Herwig Schreiner ${ }^{2}$ \\ 'Laboratório de Plasmas Tecnológicos - LaPTec, Universidade Estadual Paulista - UNESP, \\ Sorocaba, SP, Brasil \\ ${ }^{2}$ Departamento de Física - DF, Universidade Federal do Paraná - UFPR, Curitiba, PR, Brasil \\ *e-mail: drsantanapl@gmail.com
}

\begin{abstract}
In this work we discuss the wettability, chemical composition, surface morphology and optical transmittance of polyvinyl chloride (PVC) samples treated by Plasma Immersion and by Plasma Immersion Ion Implantation. The total pressure of $\mathrm{N}_{2}$ or $\mathrm{SF}_{6}$ was $6.66 \mathrm{~Pa}$, for treatments of $900 \mathrm{~s}$, applied rf power of 25 and $100 \mathrm{~W}$, and the substrate temperature was about $298 \mathrm{~K}$. In PIII, high voltage pulses of $-2400 \mathrm{~V}$ at a cycle time of $30 \mu$ s and a frequency of $300 \mathrm{~Hz}$ were used. The wettability of the samples was assessed via contact angle measurements, which indicated either hydrophilicity or hydrophobicity, depending on the plasma composition. X-ray Photoelectron Spectroscopic analysis confirmed strong fluorine attachment to the surface after treatments using $\mathrm{SF}_{6}$ plasmas, and the presence of oxygen after treatments using nitrogen plasmas. Atomic Force Microscopy images showed that the roughness Rrms, depends on the plasma conditions. Optical transmittance in the visible region, $\mathrm{T}(\lambda)$, was increased by plasma immersion. The greatest contact angle observed was $142^{\circ}$ (PI cathode), while the highest roughness was $213.2 \mathrm{~nm}$. The highest optical transmittance in the visible region was around to $90 \%$ (PI anode).
\end{abstract}

Keywords: PVC, plasma immersion techniques, contact angle, XPS, AFM, optical transmittance.

How to cite: Sant'Ana, P. L., Bortoleto, J. R. R., Cruz, N. C., Rangel, E. C., Durrant, S. F., \& Schreiner, W. H. (2020). Surface functionalization of polyvinyl chloride by plasma immersion techniques. Polimeros: Ciência e Tecnologia, 30(4), e2020044. https://doi.org/10.1590/0104-1428.06020

\section{Introduction}

Low-pressure plasma treatment, an environmentally friendly alternative to conventional methods of surface modification, can improve the surface properties of polymers without changing their bulk properties ${ }^{[1]}$. Surface modification in plasmas fed different gases has several advantages, such as a simple and rapid control of the process rate and economic efficiency ${ }^{[2]}$. Radiofrequency plasma technologies using fluorinated gases are currently employed in materials science, offering low-temperature reactions (often the treatment can be achieved at room temperature, which avoids the thermal degradation of the material). Direct fluorination is an effective method for improving the surface properties of pristine polymer materials, including barrier, gas separation and bactericide properties, adhesion, printability, chemical resistance, and biocompatibility ${ }^{[3]}$. One of the purposes of fluorinating polymers is to increase their surface hydrophobicity for use in the polymer packaging of foodstuffs, leading to improvements in anti-sticking, friction, corrosion resistance, flammability, refractive index, dielectric constant, and water/oil repellence. Improved hydrophilization is also useful since it improves adhesion in such processes as painting, coating or gluing ${ }^{[4]}$. To our best knowledge, different PI electrical configurations for the

surface functionalization of PVC have not been previously reported. Other results concerning hydrophobic/hydrophilic surface treatments of $\mathrm{PET}^{[5]}$ and $\mathrm{PVC}^{[6]}$ in low-pressure plasmas have been reported. In those treatments, plasma immersion techniques (PI) and Plasma Immersion Ion Implantation (PIII) were employed, to modify surface wetting, roughness and optical transmission. Higher contact angles were observed after plasma fluorination and lower ones after plasma nitrogenation, while maintaining low surface roughness and high transparency ${ }^{[7,8]}$. Substrate cooling was used since high substrate temperatures can reduce optical transmittance in the visible range.

In the present study, plasma immersion techniques were used to modify the surface properties of PVC, to change the wettability from intermediate to hydrophobic using fluorine plasma or to hydrophilic using nitrogen plasmas. These results are important since wettability influences the exclusion of water and the possibility of adhesion between different polymers. An additional objective was to maintain or improve the optical transparency of 'blue' PVC in the visible region, which is necessary in packaging applications, where the product must remain clearly visible. 


\section{Methods}

The experimental setup used consists of a stainless-steel vacuum chamber ( $30 \mathrm{~cm}$ in height and $25 \mathrm{~cm}$ in diameter) with two internal, horizontal, circular stainless-steel electrodes of $11 \mathrm{~cm}$ diameter. Substrates were placed on the driven or biased electrode and the system was evacuated by a rotary pump $\left(18 \mathrm{~m}^{3} / \mathrm{h}\right)$ down to $\sim 0.7 \mathrm{~Pa}$. Needle valves were employed to control the gas feed (gases of purity $99.9995 \%$ ), and a capacitive pressure sensor to monitor the chamber pressure. Samples were exposed directly to the plasma environment established by the application of radiofrequency power $(13.56 \mathrm{MHz})$ at 25 and $100 \mathrm{~W}$ for both gases $\left(\mathrm{N}_{2}\right.$ and $\left.\mathrm{SF}_{6}\right)$. Twenty four substrates of blue PVC $(2.5 \mathrm{~cm} \times 1.5 \mathrm{~cm}$, and $1 \mathrm{~cm}$ of thickness $)$ were used. Eight substrates were treated in three different rf plasma immersion modes, as indicated in previous literature ${ }^{[6-9]}$, and summarized as follows:

(i) The sample holder and the chamber walls were grounded while rf power was connected to the opposite electrode (driven electrode): PI 'anode'; (eight samples);

(ii) The rf power was connected to the sample holder (driven electrode) while the other electrode and chamber walls were grounded: PI 'cathode'; (eight samples);

(iii) The rf power was connected to the upper electrode (driven electrode) while negative pulses of high voltage were applied to the substrate holder: PIII, (eight samples).

A high voltage source (model RUP-6) and an oscilloscope (TDS from Tektroniks) were employed for the PIII experiments. The negative pulses, $-2400 \mathrm{~V}$, were supplied at $300 \mathrm{~Hz}$ and period (duty cycle) was calculated as being: $\mathrm{t}_{\mathrm{on}} /\left(\mathrm{t}_{\mathrm{on}}+\mathrm{t}_{\text {off }}\right)$, which value was $\sim 3.3 \mathrm{~ms}$ for $\mathrm{t}_{\text {on }}$ fixed to $30 \mu \mathrm{s}$, for all PIII experiments. Twelve PVC samples were treated in $\mathrm{SF}_{6}$ plasmas and twelve in $\mathrm{N}_{2}$ plasmas. Fig. 1 shows the electrical configuration of the plasma immersion and plasma immersion ion implantation techniques used in our experiments.

As temperature changes can change the optical transmittance, during treatment the sample holder was cooled with water at room temperature. Immediately after removing the treated samples from the reactor, the samples were characterized. The surface contact angle, $\Theta$, was measured using a Goniometer (100-00, Ramé- Hart) with three drops of deionized water. Ten measurements were taken for each drop. The drops had a volume of $0.6 \mu 1$. Surface morphologies of four different samples were examined using an Atomic Force Microscope
(XE-100, Park Instruments) operating in air, generating $5 \mu \mathrm{m}$ x $5 \mu \mathrm{m}$ images. From the images acquired in the noncontact mode, the root mean square roughness, $\mathrm{R}_{\mathrm{rms}}$, was calculated using the PicoView 1.2 software.

The effect of the plasma treatment on the chemical composition of the PVC surface was evaluated from X-Ray Photoelectron Spectroscopy, XPS, survey spectra. Data were collected for the untreated PVC (one sample) and plasma-treated PVC (four samples). A Microtech - ESCA 3000 Spectrometer was employed, which achieved a base pressure of $2 \times 10^{-8} \mathrm{~Pa}$. The samples were studied using $\mathrm{Mg} \mathrm{K}_{\alpha}$ radiation. A resolution of about $0.8 \mathrm{eV}$ was achieved. The spectra show intensity as function of binding energy from zero to $800 \mathrm{eV}^{[9]}$. The binding energies (BEs) of the peaks in the spectra were referenced to that of the $1 \mathrm{~s}$ electrons in carbonaceous carbon $(284.6 \mathrm{eV})^{[10]}$. Shirley background correction was used.

Optical transmittance, T $(\lambda)$, of Blue PVC was measured for six samples, using a UV-vis-NIR Spectrometer (Perkin Elmer Lambda 750) over the wavelength range from $190 \mathrm{~nm}$ to $3300 \mathrm{~nm}$. Table 1 shows the technical parameters.

\section{Results}

Table 2 shows the values of contact angles, immediately after the treatment and after 30 days (ageing). Also, the optical transmittance of visible light (at $550 \mathrm{~nm}$ ) was investigated for PVC after the different plasma treatments: PI cathode, PI anode and PIII, at low and high applied rf power using fluorine or nitrogen plasma ${ }^{[6-9]}$.

Table 1. Plasma immersion procedure conditions for the PVC samples.

\begin{tabular}{|c|c|}
\hline Substrate & $\operatorname{PVC}\left(\rho=1.3 \mathrm{~g} / \mathrm{cm}^{3}\right)$ \\
\hline \multicolumn{2}{|c|}{ PI parameters } \\
\hline Gas system & $\mathrm{SF}_{6}$ and $\mathrm{N}_{2}$ \\
\hline Base pressure $(\mathrm{Pa})$ & 0.7 \\
\hline Work pressure $(\mathrm{Pa})$ & 6.66 \\
\hline Treatment time (s) & 900 \\
\hline rf power $(\mathrm{W})$ & 25 and 100 \\
\hline Temperature $(\mathrm{K})$ & 298 \\
\hline \multicolumn{2}{|c|}{ PIII parameters } \\
\hline High voltage $(\mathrm{V})$ & -2400 \\
\hline Cycle time $(\mu \mathrm{s})$ & 30 \\
\hline Frequency $(\mathrm{Hz})$ & 300 \\
\hline
\end{tabular}

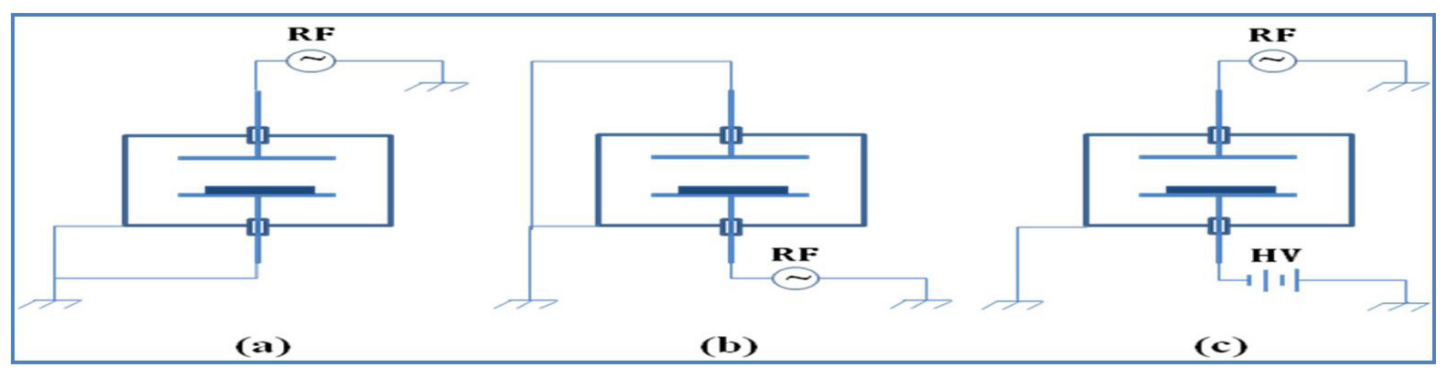

Figure 1. Electrical configuration of plasma immersion techniques applied in our experiments. (a) Plasma Immersion anode; (b) Plasma Immersion cathode; (c) Plasma Immersion Ion Implantation ${ }^{[6-9]}$. 
Table 2. Treatments took place at $25 \mathrm{~W}$ and $100 \mathrm{~W}$ and $6.66 \mathrm{~Pa}$ for $900 \mathrm{~s}$.

\begin{tabular}{ccccccc}
\hline Gas discharge & $\begin{array}{c}\text { Treatment } \\
\text { identification }\end{array}$ & $\begin{array}{c}\text { Power RF } \\
(\mathbf{W})\end{array}$ & $\begin{array}{c}\text { Plasma } \\
\text { configuration }\end{array}$ & $\begin{array}{c}\text { Initial contact } \\
\text { angle }\left({ }^{\circ}\right)\end{array}$ & $\begin{array}{c}\text { Contact angle }\left(^{\circ}\right) \\
\text { 30 days }\end{array}$ & $\begin{array}{c}\text { Transmittance } \\
\text { at 550 nm }(\mathbf{\%})\end{array}$ \\
\hline- & Virgin PVC & 0 & - & $76^{[6,9]}$ & $76 \pm 1$ & 75 \\
$\mathrm{SF}_{6}$ & Flu1 & 25 & PIII & $112 \pm 1$ & $135 \pm 2$ & 85 \\
& Flu2 & 100 & PIII & $113 \pm 1$ & $131 \pm 2$ & 85 \\
& Flu3 & 25 & Cathode & $100 \pm 1$ & $123 \pm 1$ & 85 \\
& Flu4 & 100 & Cathode & $142 \pm 2$ & $124 \pm 2$ & 84 \\
& Flu5 & 25 & Anode & $103 \pm 1$ & $123 \pm 1$ & 82 \\
$\mathrm{~N}_{2}$ & Flu6 & 100 & Anode & $102 \pm 1$ & $120 \pm 1$ & 84 \\
& Nit1 & 100 & PIII & $9 \pm 2$ & $75 \pm 1$ & 83 \\
& Nit2 & 100 & Cathode & $1 \pm 0.5$ & $74 \pm 2$ & 74 \\
\hline
\end{tabular}

PVC is a slightly hydrophobic polymer with a water contact angle of around $76^{\circ[6,9]}$. According to the data of Table 2, wettability after treatment depends on the plasma configuration. Plasma immersion using nitrogen decreases contact angles ${ }^{[5]}$, while plasma immersion using fluorine increases them ${ }^{[6]}$, independent of the plasma technique. Owing to the plasma action, the breaking of covalent chemical bonds, such as $\mathrm{C}-\mathrm{H}$ or $\mathrm{C}-\mathrm{O}$ and their subsequent recombination may lead to the formation of $\mathrm{C}-\mathrm{F}$ bonds after the fluoride treatment by $\mathrm{P}^{[5,6,9]}$ which explains the increased hydrophobic character of the polymers undergoing this treatment. For treatment by PI, the increasing power supplied to the $\mathrm{SF}_{6}$ plasma enhances ion bombardment. Thus, a greater number of fragmented species impinging on the surface offers a greater number of active sites for binding C-F, which justifies the higher $\theta$ values after fluorination ${ }^{[-9-9]}$. In the reactor there are also the effects of ionic bombardment for all PI configurations ${ }^{[9]}$. In addition, as the ageing time increases, $\Theta$ gradually recovers its initial character, particularly after treatment in nitrogen plasmas. The chemical composition of the treated material can change upon ageing. Furthermore, we believe that the structural reorganization of the polymer chains may play an important role in the modification of the polymer's wettability ${ }^{[-9,911]}$. An increase in optical transmittance was observed for the different plasma configurations, except for sample 'Nit2', which used a nitrogen plasma in the 'cathode' mode.

\subsection{Effect of ageing on $\theta$}

This section discusses the evolution of contact angles as a function of ageing time for samples treated by plasma immersion and plasma immersion ion implantation, using $\mathrm{SF}_{6}$ and $\mathrm{N}_{2}$, respectively, under different conditions. After fluorination treatments the contact angles were stable over time, while the nitrogen treatments presented a clear tendency to become hydrophobic. After treatment, short chain molecules reorient towards the surface and oxidized functional groups may diffuse into the interior of the material ${ }^{[12]}$. The literature also indicates that ageing causes the incorporation of oxygen as $\mathrm{C}-\mathrm{O}$ and $\mathrm{C}=\mathrm{O}$, and also as $-\mathrm{OH}$. This is typical of plasma polymers, which upon deposition usually have a high density of free-radicals that react with oxygen and water vapor. As mentioned previously, immediately after being withdrawn from the reactor, samples treated with nitrogen are highly hydrophilic. This wettability was linked to the chemical composition obtained by XPS. Incorporation of oxygencontaining polar groups explains the wettability of samples

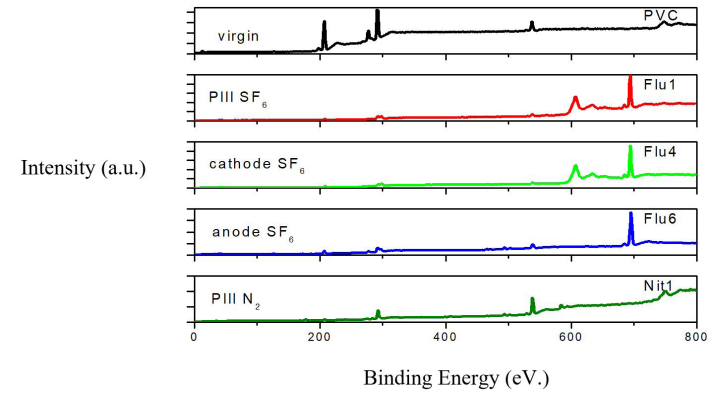

Figure 2. XPS survey spectra of untreated PVC and PVC treated under different conditions: PIII associated with fluorine or nitrogen treatment, and PI associated with fluorine treatment (cathode or anode electrical configuration).

treated with nitrogen ${ }^{[5-9,13]}$. The use of reactive nitrogen plasma surface modification promotes an increase in surface hydrophilicity. As a result of the high instability of the species generated during and after plasma modification, however, the hydrophilic properties achieved by plasma surface modification are quickly lost. This process is well known as hydrophobic recovery ${ }^{[14]}$. Changes in contact angle with ageing can be much smaller for polymers that contain many crosslinks since these limit the mobility of polymeric chains ${ }^{[15]}$ and therefore impede the reorganization of polar groups ${ }^{[9]}$.

\subsection{Composition (XPS analysis)}

As is clear from Fig. 2, treatment in $\mathrm{SF}_{6}$ plasmas introduces fluorine into the treated polymer surfaces.

For virgin PVC the following peaks were observed in the spectra: C 1s located at $300 \mathrm{eV}, \mathrm{Cl} 2 \mathrm{~s}$ at $\sim 280 \mathrm{eV}$ and $\mathrm{O} 1 \mathrm{~s}$ at $\sim 538 \mathrm{eV}$. After fluorination, $\mathrm{C} 1 \mathrm{~s}$ was set to $300 \mathrm{eV}$, $\mathrm{Cl} 2 \mathrm{~s}$ at $280 \mathrm{eV}, \mathrm{O} 1 \mathrm{~s}$ at $540 \mathrm{eV}$ and $\mathrm{F} 1 \mathrm{~s}$ at $695 \mathrm{eV}$. After nitrogen ion implantation, $\mathrm{C} 1 \mathrm{~s}$ was located at $292 \mathrm{eV}, \mathrm{Cl} 2 \mathrm{~s}$ at $274 \mathrm{eV}, \mathrm{O} 1 \mathrm{~s}$ at $538 \mathrm{e} \mathrm{V}$, and $\mathrm{N} 1 \mathrm{~s}$ was located at $408 \mathrm{eV}^{[9]}$. After the treatment, XPS analyses revealed the following: carbon, oxygen, nitrogen and chlorine at, respectively, 52 at.(\%), 33 at.(\%), 12 at.(\%) and 3 at.(\%). In this situation, $\Theta$ changed from $9^{\circ}$ (immediately after the treatment) to $102^{\circ}$ after 30 days. The corresponding atomic concentrations for the untreated and treated PVC are presented in Table 2 (which also shows the binding energies). $\mathrm{PVC}$ is composed of about (50 at.\%) carbon, (38 at.\%) chlorine and few percent hydrogen ${ }^{[9,16]}$. As hydrogen is not detected by XPS, the atomic concentrations obtained for the untreated PVC are consistent. A small amount ( 11 at.\%) of oxygen is detected 
even in the as-received material ${ }^{[17]}$. After the fluorination treatment the oxygen content did not change, except for the cathode configuration at $100 \mathrm{~W}$, where it was only 3 at.(\%). Nevertheless, substantial fluorine incorporation was observed, while chlorine was removed, (virgin PVC contained 38 at. $(\%) \mathrm{Cl}$, and after $\mathrm{SF}_{6}$ bombardment, this had decreased to about 2 at.(\%). These results support the explanation of the wettability and the fluorination mechanism ${ }^{[5,6]}$. Substitution of fluorine, displacing chlorine or hydrogen atoms in polymers decreases their surface energy because of the strong covalence and small polarizability of the C-F bonds. The surface energy of a material depends on the character of terminal groups, and decreases from $-\mathrm{CH}_{2} \rightarrow-\mathrm{CH} \rightarrow-\mathrm{CF} \rightarrow-\mathrm{CF}_{3}$. Nevertheless, the presence of fluorinated groups $\left(\mathrm{CF}, \mathrm{CF}_{2}\right.$ and $\left.\mathrm{CF}_{3}\right)$ and the subsequent surface energy decrease are not enough to reach superhydrophobicity ${ }^{[5]}$. Flat surfaces terminated with $-\mathrm{CF}_{3}$ groups, which have the lowest free energy, exhibit a maximum contact angle of around $120^{\circ[16]}$. On the other hand, when nitrogen ions were implanted into the surface of PVC, the oxygen content increased, from 11 at. $\%$ to 33 at. $\%$. It is believed that residual oxygen bonds with active sites on the surface caused by ion bombardment. After nitrogen plasma immersion ion implantation the surface composition was as follows: $(52 \% \mathrm{C}),(33 \% \mathrm{O}),(12 \% \mathrm{~N})$ and $(3 \% \mathrm{Cl})$. For sample Nit1 (PIII), hydrophilization may be caused by the formation of oxygen-containing groups ${ }^{[5,7-9]}$. The high concentration of oxygen is consistent with the reduction in $\theta$. The binding energy of O 1s observed for virgin PVC and PVC treated with nitrogen is the same: $538 \mathrm{eV}$. Under these conditions there is expected to be a high degree of bond fragmentation and the emission of species from the solid. As hydrogen and chlorine atoms are side groups in PVC, they are very prone to be lost upon bombardment ${ }^{[6]}$. Carbon atoms can also be ejected and $\mathrm{O}$ incorporation can be observed. Free radicals generated by $\mathrm{Cl}$ and $\mathrm{H}$ emission can react with atmospheric $\mathrm{H}_{2} \mathrm{O}$ and $\mathrm{O}_{2}$, thereby incorporating oxygen groups.

\subsection{Surface morphology}

Another property of great importance in the wettability of solids is surface roughness ${ }^{[18]}$. Roughness alters the contact area between the liquid drop and the surface, resulting in higher values of $\theta$ in hydrophobic materials and lower ones in hydrophilic surfaces ${ }^{[19]}$. To investigate the morphology of PVC, two-dimensional AFM images $(5 \mu \mathrm{m} \times 5 \mu \mathrm{m})$ were obtained for the untreated and treated PVC, as shown in Fig. 3. Although the tip of equipment is very fine and the spatial resolution should be high, the images are not all as well-defined as was expected.

The roughness of the non-treated PVC (a) is $7.8 \mathrm{~nm}$. According to Fig. 3a, virgin PVC possesses a high density of pinholes ${ }^{[16]}$, which is caused by the absence of polymeric chains in those regions. These pinholes have depths of a few nanometers, being of the same order as the $\mathrm{R}_{\mathrm{rms}}$ of PVC $(7.8 \mathrm{~nm})$. In relation to PVC treated by plasma immersion, Fig. $3 \mathrm{~b}$, there is a considerable increase in roughness, to about $213.2 \mathrm{~nm}$, which reinforces the explanation of the increase in hydrophobicity. Increased cross-linking between the neighboring polymer chains has reduced the presence of pinholes. This usually occurs when acquiring images of polymers. In relation to virgin PVC, there was a small increase in roughness for the sample treated by PIII; $27.3 \mathrm{~nm}$ at 25 W. As shown in Fig. 3d, there was no significant reduction in the density of pinholes, which implies a relatively low

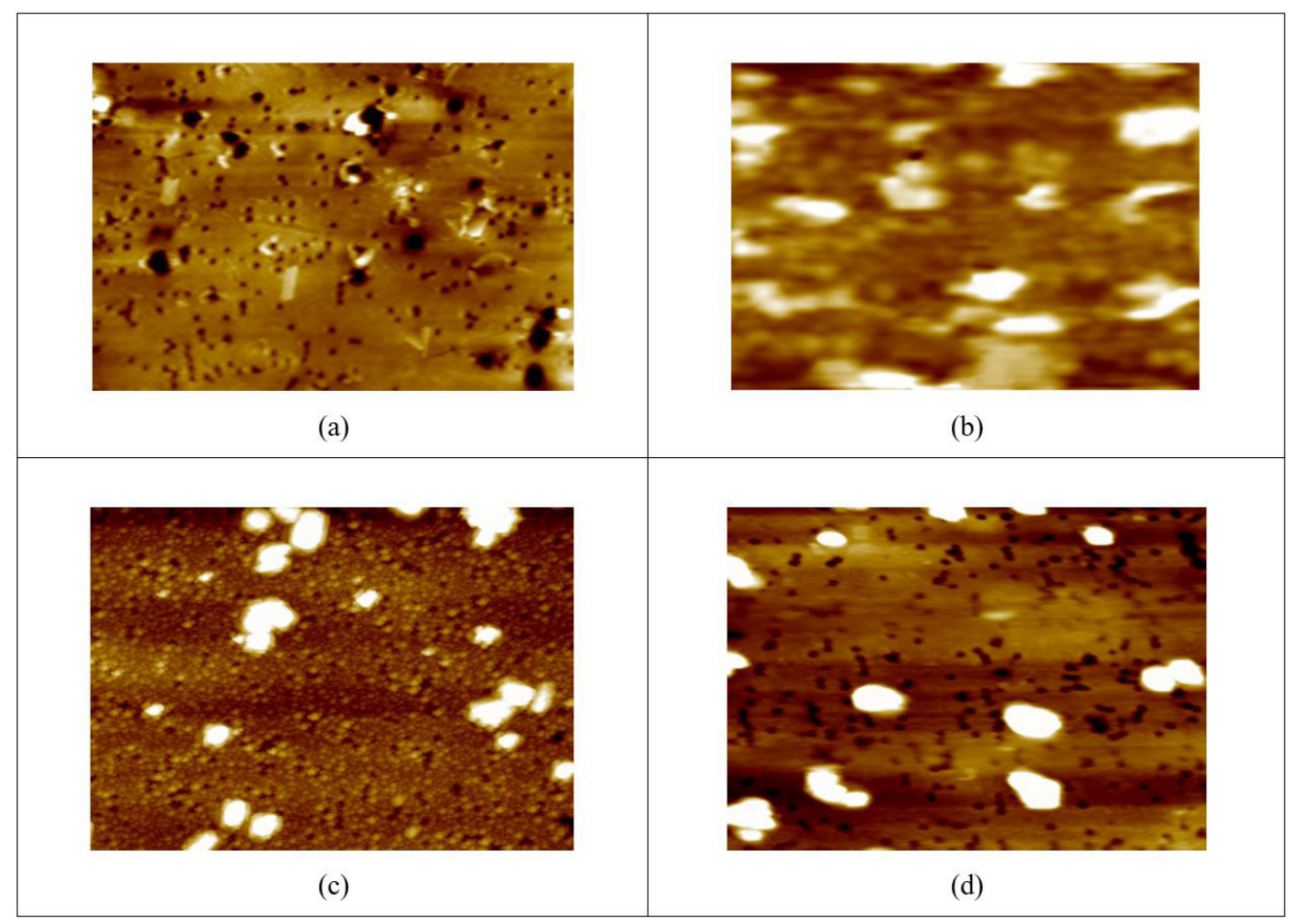

Figure 3. AFM images of: (a) Virgin PVC surface, $\mathrm{R}=7.8 \mathrm{~nm}$ [20]; Plasma treatments in $\mathrm{SF}_{6}$ (b) Flu4: PI (cathode) $100 \mathrm{~W}$, $\mathrm{R}=213.2 \mathrm{~nm}$ (c) Flu1: PIII 25W, R=27.3 nm and (d) Flu6: PI (anode) $100 \mathrm{~W} \mathrm{R}=18.7 \mathrm{~nm}^{[9]}$. 


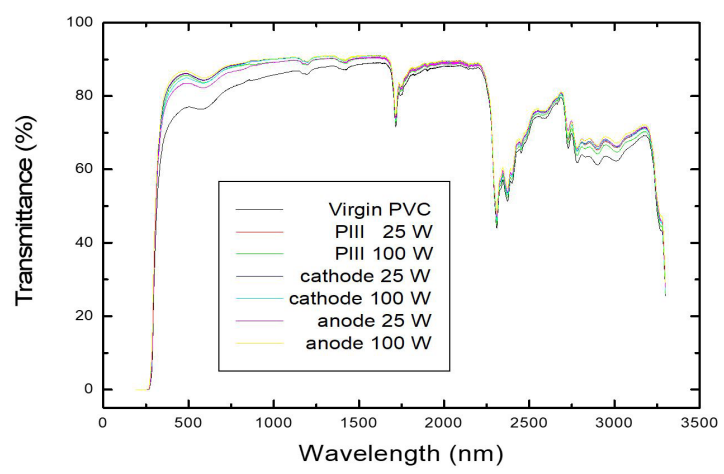

Figure 4. Optical transmittance as function of wavelength for blue PVC treated using $\mathrm{SF}_{6}$ under different conditions: PIII $25 \mathrm{~W}$ or $100 \mathrm{~W}$; PI cathode $25 \mathrm{~W}$ or $100 \mathrm{~W}$; and PI anode $25 \mathrm{~W}$ or $100 \mathrm{~W}$ (Flu 1 to Flu6).

number of lateral links, or a lower degree of intertwining. The roughness was $18.7 \mathrm{~nm}$.

The polymer surface in the plasma is exposed to a broad spectrum of ions, electrons, excited neutrals, radicals, visible and ultraviolet radiation that cause etching and, consequently, increase surface roughness and change surface chemistry. Plasma roughening, however, was not regarded as a method for producing useful patterns. Recent published work has changed this view, and in fact, interesting regular surface topographies after plasma treatment of polymer surfaces under defined conditions have recently been reported ${ }^{[20]}$.

In all cases, we hypothesize that on the surface of treated PVC, pointed peaks are aligned, like a "grass". For roughnesses of a few tens of nanometers, we characterize the surface as smooth. Both treated and untreated PVC have low roughnesses, producing low reflectance.

\subsection{Optical transmittance $-T(\lambda)$}

Fig. 4 shows the optical transmittance spectra of blue $\mathrm{PVC}$ treated with $\mathrm{SF}_{6}$ under different conditions. Each spectrum was generated at high resolution, $\sim 0.2 \mathrm{~nm} /$ pixel.

Whatever the treatment, the transmittance of all blue PVC samples in visible light increased. PIII is most appropriate for maintaining high transparency in the visible. Thus, plasma treatment distinctively influenced the transmittance of blue PVC. At high powers there is a greater fragmentation of molecules, and subsequent recombination between different plasma species, causing greater distortions of the polymer chains, thus producing voids among them, which increase the mean free path of the incident radiation. This effect, however, was limited owing to the low temperature treatment ${ }^{[7,8]}$.

\section{Discussions}

\subsection{Physico-chemical modifications}

After fluorine insertion into the polymer backbone, the surface becomes hydrophobic. Although C-F bonds are highly polar, when these species are present on the surface of a material, they will increase its hydrophobicity. The repulsion between the oxygen in the water and the fluoride surface is greater than attraction of the fluorine for hydrogen, which implies a non-chemical attraction between the fluorinated surface and the test fluid ${ }^{[21]}$. The incorporation of fluorine resulted in the formation of different functional groups on the surface, such as $\mathrm{CF}, \mathrm{CHF}, \mathrm{CF}_{2}$ and $\mathrm{CF}_{3}{ }^{[22]}$. Two factors were instrumental in the increase of hydrophobicity: (i) the degree of fluorination; (ii) the surface roughness ${ }^{[5]}$. The degree of wetting of the samples immediately after treatment has its effect amplified by the increased surface roughness, which increases the area available for ions or even for neutral species from the plasma to bind chemically with the surface atoms. On the other hand, the main mechanism responsible for the hydrophilic behavior of the samples treated with $\mathrm{N}_{2}$, is the incorporation of polar groups ${ }^{[5-9,16]}$. Although the treatment results in the incorporation of polar groups, polymer wettability does not involve only oxidative reactions. Loss and incorporation of new species, other than O, may occur as ageing time increases ${ }^{[23]}$. XPS analysis shows an increase in [O] from 11 at.\% to 33 at.\% on PVC samples after $\mathrm{N}_{2}$ treatment by PIII. This leads to the hypothesis that the presence of oxygen in the reactor, deriving either from residual gas or gas released from the glass chamber near the electrode region, may also account for the hydrophilization process $^{[12,13]}$. Chemical modifications can occur upon ageing and reorganize chemical groups of the polymeric chains, which favor the reduction of the surface free energy until chemical stabilization occurs. Thus, the stability of the treated surface is determined by the extent to which polar species are allowed to move. A way of restraining reorientation is by an increase in cross-linking ${ }^{[24]}$, which may be produced by ion implantation. An increase in the density of covalent bonds among neighboring chains, known as anchor points, limits vibrational and rotational movements. As a consequence, the polymer structure becomes strongly connected and the backbone more rigid ${ }^{[9,16]}$.

The change in the surface hydrophilicity is caused by the replacement of $\mathrm{C}-\mathrm{C}$ or $\mathrm{C}-\mathrm{H}$ group on the surface of $\mathrm{PVC}$ by $\mathrm{C}-\mathrm{O}$ or $\mathrm{C}=\mathrm{O}$ groups ${ }^{[25-29]}$. A small quantity of nitrogen was detected on the treated sample surface and may be caused by atmospheric $\mathrm{N}_{2}$ reacting with the active surface functional groups $^{[30]}$. Interactions between the nitrogen and the surface can also result in the diffusion of the nitrogen on the substrate surface ${ }^{[31]}$. Indeed, the XPS analysis (sample Nit1), presents a low $\mathrm{N}$ concentration after PIII ${ }^{[32]}$. Hydrogen atoms may also be liberated from the polymer, causing cross-linking. For engineering applications, the degree of cross-linking and scission as well the depth of the modified layer can be tailored by the electronic-to-nuclear interactions via a judicious choice of ion species and ion energy ${ }^{[33]}$. Experimental results suggest that unsaturation can occur when ion pairs in two neighboring chains overlap ${ }^{[34]}$. Although both electronic and nuclear processes cause cross-linking as well as scissions, it has been found that the most important parameter to achieve a high degree of cross-linking is electronic, while nuclear collisions tends to cause degradation ${ }^{[35]}$.

Correlating the three different plasma immersion configurations with the wettability results, the key parameters are seen to be the ion flux and energy. When the sample is placed on the driven electrode (PI cathode), the self-bias will guarantee a high average negative potential relative to the plasma, so that the energy of the ions reaching the sample holder will be high, causing high recombination rates and 
therefore high production rates of C-F bonds in fluorinecontaining plasmas. However, when the substrate holder is grounded together with the chamber walls (PI anode), the average potential drop in electrode sheath is not so high. In PIII ion energy is controlled by the HV pulses, being much more intense than in PI configurations. Another important point is that $\mathrm{PVC}$ is an insulating material. Consequently, independent of the substrate holder potential, the sample will be at floating potential, and possibly the charged particle flux onto the sample is not so different in the three PI configurations when the sample is at floating potential. Thus $\theta$ is influenced much more by ion energy than by the ion flux of charged particles.

\subsection{Spectroscopy}

The increase in optical transmittance of polymers can be explained by changes in chemical structures and bonds that occur on the surface of samples owing to rf plasma treatment. Under plasma treatment some bonds in the polymer structure will break and some new chains will form. In this case, plasma treatment may affect optical properties of the material ${ }^{[5-9,16]}$. Summarizing, PIII did not change optical transmittance, that is, the samples treated at the same rf power of $100 \mathrm{~W}$ presented high optical transmittance for $\mathrm{SF}_{6}$ plasma or $\mathrm{N}_{2}$ plasmas, affecting only the wettability (samples Nit1 vs. Flu2). On the other hand, PI cathode changed the wettability, presenting the most extreme values of $\Theta,\left(1^{\circ}\right.$ for nitrogen plasma; $142^{\circ}$ for fluorine plasmas). In addition, the PI cathode treatment at $\mathrm{rf}=100 \mathrm{~W}$ changed the optical transmittance only for the sample treated with fluorine-containing plasmas (Flu4), producing an increase in optical transmittance from $75 \%$ to $84 \%$ in the visible range. Moreover it is possible with fluorine ion implantation to maintain the low roughness, which presented a slight increase of $10 \mathrm{~nm}$ (sample Flu1), or even to considerably increase the roughness from 7.8 to $213.2 \mathrm{~nm}$ using PI cathode (sample Flu3).

\section{Conclusions}

Plasma treatments of PVC samples can increase hydrophobicity by using $\mathrm{SF}_{6}$ or increase hydrophilicity using $\mathrm{N}_{2}$. AFM images showed that low energy ion implantation is more effective in maintaining the original low roughness of the polymer surface. Thus, roughness did not significantly affect the high transmittance of blue PVC. When plasma treatment increased the surface roughness, the incorporated surface species increased the change in wettability for all samples. The pinholes typically present in PVC substrates were only suppressed when the PI cathode (sample Flu4) was employed. Roughnesses were of a few nanometers, and influenced the optical properties. XPS analysis revealed the surface incorporation of fluorine for all techniques that used $\mathrm{SF}_{6}$. No significant nitrogenation of PVC was observed in nitrogen plasmas but considerable amounts of oxygen were introduced into the treated surface. Optical transmittance was increased for all plasma-treated samples. More specifically, PI cathode and PIII plasmas with fluorine produced hydrophobicity and maintained high optical transparency. The chemical composition was influential in changing the transmittance, causing a decrease in the absorption coefficient.

\section{Acknowledgements}

The authors are grateful to the Brazilian agencies Fundação de Amparo à Pesquisa do Estado de São Paulo - FAPESP (Project 2017/15853-0) and Conselho Nacional de Desenvolvimento Científico e Tecnológico - CNPq for financial support. This study was also financed in part by Coordenação de Aperfeiçoamento de Pessoal de Nível Superior - Brasil, CAPES - Finance Code 001.

\section{References}

1. Juang, R. S., Hou, W. T., Huang, Y. C., Tseng, Y. C., \& Huang, C. (2016). Surface hydrophilic modifications on polypropylene membranes by remote methane/oxygen mixture plasma discharges. Journal of the Taiwan Institute of Chemical Engineers, 65, 420-426. http://dx.doi.org/10.1016/j.jtice.2016.04.032.

2. Nazarov, V. G., Stolyarov, V. P., \& Gagarin, M. V. (2014). Simulation of chemical modification of polymer surface. Journal of Fluorine Chemistry, 161, 120-127. http://dx.doi. org/10.1016/j.jfluchem.2014.01.021.

3. Kharitonov, A. P., Simbirtseva, G. V., Tressaud, A., Durand, E., Labrugère, C., \& Dubois, M. (2014). Comparison of the surface modifications of polymers induced by direct fluorination and rf-plasma using fluorinated gases. Journal of Fluorine Chemistry, 165, 49-60. http://dx.doi.org/10.1016/j. jfluchem.2014.05.002.

4. Gancarz, I., Bryjak, M., Kujawski, J., Wolska, J., Kujawa, J., \& Kujawski, W. (2015). Plasma deposited fluorinated films on porous membranes. Materials Chemistry and Physics, 151, 233-242. http://dx.doi.org/10.1016/j.matchemphys.2014.11.059.

5. Sant'Ana, P. L., Bortoleto, J. R. R., Cruz, N. C., Rangel, E. C., \& Durrant, S. F. (2017). Study of wettability and optical transparency of PET polymer modified by plasma immersion techniques. Revista Brasileira de Aplicações de Vácuo, 36(2), 68-74. http://dx.doi.org/10.17563/rbav.v36i2.1050.

6. Sant'Ana, P. L., Prestes, S. M. D., Mancini, S. D., Rangel, R. C., Bortoleto, J. R. R., Cruz, N. C., Rangel, E. C., \& Durrant, S. F. (2019). Comparative analysis between the degree of wettability of recycled PVC and PET polymers treated by immersion or deposition of organic films in fluorinated plasmas. Revista Brasileira de Aplicações de Vácuo, 37(3), 120-128. http://dx.doi.org/10.17563/rbav.v37i3.1115.

7. Sant'Ana, P. L., Bortoleto, J. R. R., Rangel, E. C., Cruz, N. C., Durrant, S. F., Botti, L. C. M., Anjos, C. R., Teixeira, V., Azevedo, S., Silva, C. I., Soares, N. F. F., \& Medeiros, E. A. A. (2018). Surface properties of PET polymer treated by plasma immersion techniques for food packaging. International Journal of Nano Research, 1(1), 33-41. Retrieved in 2020, August 17, from https://www.innovationinfo.org/international-journalof-nano-research/article/Surface-Properties-of-PET-PolymerTreated-by-Plasma-Immersion-Techniques-for-Food-Packaging

8. Sant'Ana, P. L., Bortoleto, J. R. R., Cruz, N. C., Rangel, E. C., Durrant, S. F., Botti, L. C. M., Anjos, C. A. R., Medeiros, E. A. A., Soares, N. F. F., Azevedo, S., Teixeira, V., Carneiro, J., \& Silva, C. I. (2018). Surface properties and morphology of PET treated by plasma immersion ion implantation for food packaging. Nanomedicine \& Nanotechnology Open Access, 3(3), 1-13. http://dx.doi.org/10.23880/NNOA-16000145.

9. Sant'Ana, P. L. (2018). Polymers treated by plasma for optical devices and food packaging. Mauritius: Scholar's Press.

10. Cruz, S. A., Zanin, M., Nascente, P. A. P., \& Bica de Moraes, M. A. (2010). Superficial modification in recycled PET by plasma etching for food packaging. Journal of Applied Polymer Science, 115(5), 2728-2733. http://dx.doi.org/10.1002/app.29958. 
11. Milella, A., Colapricio, V., Favia, P., Iacobelli, L., \& d'Agostino, R. (2001). Plasma treatments of polymers for reducing ageing. In Proceedings of the 15th International Symposium on Plasma Chemistry (pp. 2416-2420). Orléans, France: International Plasma Chemistry Society. Retrieved in 2020, August 17, from https://www.ispc-conference.org/ispcdocs/ispc15/ content/15/15-2416.pdf

12. Foerch, R., Kill, G., \& Walzak, M. (1993). Plasma surface modification of polypropylene: shortterm vs. Long-term plasma treatment. Journal of Adhesion Science and Technology, 7(10), 1077-1089. http://dx.doi.org/10.1163/156856193X00592.

13. Dong, H., \& Bell, T. (1999). State-of-the-art overview. Ion beam surface modification of polymer towards improving tribological properties. Surface and Coatings Technology, 111(1), 29-40. http://dx.doi.org/10.1016/S0257-8972(98)00698-7.

14. Huang, C., Ma, W. C., Tsai, C. Y., Hou, W. T., \& Juang, R. S. (2013). Surface modification of polytetrafluorethylene membranes by radio frequency methane/nitrogen mixture plasma polymerization. Surface and Coatings Technology, 231, 42-46. http://dx.doi.org/10.1016/j.surfcoat.2012.03.005.

15. Sadeek, S. A. (2005). Synthesis, thermogravimetric analysis, infrared, electronic and mass spectra of $\mathrm{Mn}(\mathrm{II}), \mathrm{Co}(\mathrm{II})$ and $\mathrm{Fe}(\mathrm{III})$ norfloxacin complexes. Journal of Molecular Structure, 753(1-3), 1-12. http://dx.doi.org/10.1016/j.molstruc.2005.06.011.

16. Zha, J., Ali, S. S., Peyroux, J., Batisse, N., Claves, D., Dubois, M., Kharitonov, A. P., Monier, G., Darmanin, T., Guittard, F., \& Alekseiko, L. N. (2017). Superhydrophobic of polymer films via fluorine atoms covalent attachment and surface nano-texturing. Journal of Fluorine Chemistry, 200, 123-132. http://dx.doi.org/10.1016/j.jfluchem.2017.06.011.

17. Rangel, E. C., dos Santos, N. M., Bortoleto, J. R. R., Durrant, S. F., Schreiner, W. H., Honda, R. Y., Rangel, R. C. C., \& Cruz, N. C. (2006). Treatment of PVC using an alternative low energy ion bombardment procedure. Applied Surface Science, 258(5), 1854-1861. http://dx.doi.org/10.1016/j.apsusc.2011.10.061.

18. Nakae, H., Iuni, R., Hirata, Y., \& Saito, H. (1998). Effects of surface roughness on wettability. Acta Materialia, 46(7), 23132318. http://dx.doi.org/10.1016/S1359-6454(97)00387-X.

19. Hazlett, R. D. (1992). On surface roughness effects in wetting phenomena. Journal of Adhesion Science and Technology, 6(6), 625-633. http://dx.doi.org/10.1163/156856192X01006.

20. D’Sa, R. A., Burke, G. A., \& Meenan, B. J. (2010). Protein adhesion and cell response on atmospheric pressure dielectric barrier discharge-modified polymer surfaces. Acta Biomaterialia, 6(7), 2609-2620. http://dx.doi.org/10.1016/j.actbio.2010.01.015. PMid:20096386.

21. Sant'Ana, P. L. (2014). Commercial polymers treated by plasma for optical devices and food packaging (Doctoral thesis). Universidade Estadual Paulista, Sorocaba.

22. Vandencasteele, N., Fairbrother, H., \& Reniers, F. (2005). Selected effect of the ions and the neutrals in the plasma treatment of PTFE surfaces: an OES-AFM-contact angle and XPS study. Plasma Processes and Polymers, 2(6), 493-500. http://dx.doi.org/10.1002/ppap.200500010.

23. Gengenbach, T. R., \& Griesser, H. J. (1999). Post-deposition ageing reactions differ markedly between plasma polymers deposited from siloxane and silazane monomers. Polymer, 40(18), 5079-5094. http://dx.doi.org/10.1016/S0032-3861(98)00727-7.

24. Yasuda, H., Sharma, A., \& Yasuda, T. (1981). Effect of orientation and mobility of polymer molecules at surfaces on contact angle and its hysteresis. Journal of Polymer Science. Polymer Physics Edition, 19(9), 1285-1291. http://dx.doi. org/10.1002/pol.1981.180190901.
25. Chu, P. K. (2004). Recent Developments and applications of plasma immersion ion implantation (PIII). Journal of Vacuum Science \& Technology. B, Microelectronics and Nanometer Structures : Processing, Measurement, and Phenomena : An Official Journal of the American Vacuum Society, 22(1), 289296. http://dx.doi.org/10.1116/1.1632920.

26. Chu, P. K., Tang, B. Y., Wang, L. P., Wang, X. F., Wang, S. Y., \& Huang, N. (2001). Third-generation plasma immersion ion implanter for biomedical materials and research. The Review of Scientific Instruments, 72(3), 1660-1665. http://dx.doi. org/10.1063/1.1340029.

27. Guruvenket, S., Rao, G. M., Komath, M., \& Raichur, A. M. (2004). Plasma surface modification of polystyrene and polyethylene. Applied Surface Science, 236(1-4), 278-284. http://dx.doi.org/10.1016/j.apsusc.2004.04.033.

28. Triandafillu, K., Balazs, D. J., Aronsson, B. O., Descouts, P., Tu Quoc, P., van Delden, C., Mathieu, H. J., \& Harms, H. (2003). Adhesion of pseudomonas aeruginosa strains to untreated and oxygen-plasma treated poly(vinyl chloride) (PVC) from endotracheal intubation devices. Biomaterials, 24(8), 15071518. http://dx.doi.org/10.1016/S0142-9612(02)00515-X. PMid:12527292.

29. Park, Y. W., \& Inagaki, N. (2003). Surface modification of poly (vinylidene fluoride) film by remote $\mathrm{Ar}, \mathrm{H}_{2}$, and $\mathrm{O}_{2}$ plasmas. Polymer, 44(5), 1569-1575. http://dx.doi.org/10.1016/S00323861(02)00872-8.

30. Zhang, W., Chu, P. K., Ji, J., Zhang, Y., Liu, X., Fu, R. K., Ha, P. C., \& Yan, Q. (2006). Plasma surface modification of poly vinyl chloride for improvement of antibacterial properties. Biomaterials, 27(1), 44-51. http://dx.doi.org/10.1016/j. biomaterials.2005.05.067. PMid:16005957.

31. Santjojo, D. J., Istiroyah, T., \& Aizawa, T. (2015). Dynamics of nitrogen and hydrogen species in a high rate plasma nitriding of martensitic stainless steel. In: Proceedings of the 9th South East Asia Technical University Consortium - SEATUC (pp. 311-314). Nakhon Ratchasima, Thailand: Suranaree University of Technology.

32. Choudhury, A. J., Barve, S. A., Chutia, J., Pal, A. R., Chowdhury, D., Kishore, R., Jagannath, Mithal, N., Pandey, M., \& Patil, D. S. (2011). Investigations of the hydrophobic and scratch resistance behavior of polystyrene films deposited on bell metal using RF-PACVD process. Applied Surface Science, 257(9), 4211-4218. http://dx.doi.org/10.1016/j.apsusc.2010.12.022.

33. Klapperich, C., Komvopoulos, K., \& Pruitt, K. (1999). Tribological properties and microstructure evolution of ultra-high molecular weight polyethylene. Journal of Tribology, 121(2), 394-402. http://dx.doi.org/10.1115/1.2833952.

34. Lee, E. H., Rao, G. R., \& Mansur, L. (1996). Super-hard-surfaced polymers by high-energy ion-beam irradiation. Trends in Polymer Science (Regular Ed.), 4(7), 229-237.

35. Lee, E. H. (1999).Ion-beam modification of polymeric materials - fundamental principles and applications. Nuclear Instruments \& Methods in Physics Research. Section B, Beam Interactions with Materials and Atoms, 151(1-4), 29-41. http://dx.doi. org/10.1016/S0168-583X(99)00129-9.

Received: Dec. 17, 2020

Revised: Jan. 25, 2021

Accepted: Feb. 05, 2021 